\title{
Study of Hybrid Energy Storage System for High Rate Power Mitigation in Microgrid
}

\author{
Pinit WONGDET and Boonruang MARUNGSRI \\ School of Electrical Engineering, Suranaree University of Technology, Thailand \\ ${ }^{*}$ Corresponding author
}

\begin{abstract}
Energy storage system (ESS) is integrated to a microgrid for managing the intermittent power from the renewable energy source. The battery energy storage system (BESS) is widely used in a microgrid, but it has various factors such as a high current of discharge/charge that affect the lifespan and quality of the BESS and lead the extravagant investment for replacing the BESS. This paper studies the using HESS consist of BESS and supercapacitor (SC). The SC well operates at the high rapid change of current of discharge/charge. The study was performed in MATLAB/Simulink program. The study results showed the HESS application to accommodate the quick change of load variation or the fluctuation of distributed generator (DG) output that help to reduce the fluctuation in the microgrid. This method can improve power and reduce the stress on BESS for dilating the lifespan.
\end{abstract}

Keywords-hybrid energy storage system; battery; supercapacitor; lifespan of bess; microgrid

\section{INTRODUCTION}

Microgrids provide effective management for integrating DG and different load cluster. In case of grid-connected mode, microgrids connect with the main grid to ensure the microgrid has stability. Microgrids want to match the load demand and power generation. The microgrids may failure when the high power mismatch occurs and also lead the main grid to instability if there are many failed microgrid. To managing this problem, the ESS technology is used. The BESS is one of the most popular used in microgrid due to high energy density and high efficiency. However, the BESS has various factors affect the number of lifespans and its operation such as the high current of charge/discharge, depth of discharge (DOD), temperature and voltage operation $[1,2,3]$. Therefore, reduction in the rapid change of current on BESS is preferred. Recently, the HESS has been studied to combines the advantages of various energy storage technologies. Table 1 summarizes the characteristic of different energy storage technologies $[4,5]$.

TABLE I. CHARACTERISTICS OF ENERGY STORAGE TECHNOLOGIES

\begin{tabular}{|c|c|c|c|c|c|}
\hline & $\begin{array}{c}\text { Energy } \\
\text { density } \\
{[\mathrm{Wh} / \mathrm{kg}]}\end{array}$ & $\begin{array}{c}\text { Power density } \\
{[\mathrm{W} / \mathrm{kg}]}\end{array}$ & $\begin{array}{c}\text { Continuous } \\
\text { Discharge } \\
\text { time }\end{array}$ & $\begin{array}{c}\text { Response } \\
\text { time }\end{array}$ & $\begin{array}{c}\text { Cycle } \\
\text { time }\end{array}$ \\
\hline Flywheel & $5-50$ & $400-4000$ & $\mathrm{~s}-\mathrm{min}$ & $<1 \mathrm{~s}$ & 10000 \\
\hline Lead-acid & $30-50$ & $75-300$ & min-3h & $<10 \mathrm{~s}$ & 2000 \\
\hline Li-ion & $70-200$ & $150-500$ & min-5h & $<10 \mathrm{~s}$ & $<10000$ \\
\hline SC & $0.5-10$ & $1000-18,000$ & $\mathrm{~s}-1 \mathrm{~h}$ & $<1 \mathrm{~s}$ & $>100000$ \\
\hline SMES & $1-10$ & $500-2000$ & $\mathrm{~ms}-1 \mathrm{~h}$ & $<5 \mathrm{~ms}$ & $>100000$ \\
\hline
\end{tabular}

The HESS consists of the BESS and SC has been studied in the most of HESS development. The HESS combines the high energy density of BESS and high power density of SC can be widely used in many operations. As in [6], the author presented the design of HESS for regulation services in the microgrid. In [7], the author presented the probabilistic approach for power capacity specification of wind energy storage systems. His results showed that the intermittent of wind energy could reduce the lifespan of BESS and compare with SC integration. After that, he determined the size of BESS and SC for using with a wind generator. In [8], proposed the HESS to mitigate the impact of power exchanges on the lifespan of the BESS. He also presented the HESS topology and discussed the technological advancements of the HESS in the standalone microgrid.

The study of HESS application in a grid-connected mode to keep the constant of the power exchanges between a microgrid and main grid considering the factors affect the lifespan of BESS were elucidated. Section 2 presents the objective of a 
grid-connected microgrid with DG and ESS integration. Section 3 mentions the HESS application and control strategy. Section 4 shows the simulation results and discussion. Finally, the conclusion is given in Section 5.

\section{MICROGRID AND ENERGY STORAGE SYSTEMS}

A microgrid is a small power system that comprises the distributed generator such as photovoltaic and wind generator and the distributed energy storage systems. A microgrid can operate two modes that are grid- connected mode and islanded mode. Standalone mode is a microgrid that operates in islanded mode all the time. A microgrid aims to balance the power generation and the load demand in itself. For the grid-connected mode, a microgrid connects with the main grid for enhancing the reliability and the stability. Fig. 1 shows a diagram of the microgrid with the installation of ESS. The DG side ESS is used for mitigating the fluctuation of DG to smooth power output as shown in Fig. 1 (a). The DG and ESS connect to DC link before convert to the grid by the inverter. As in Fig. 1 (b), shows the load side ESS for reducing the influence of the load variation. This method can support the microgrid from the impact of load variation because high rate power change of the load may lead microgrid to failure [4].

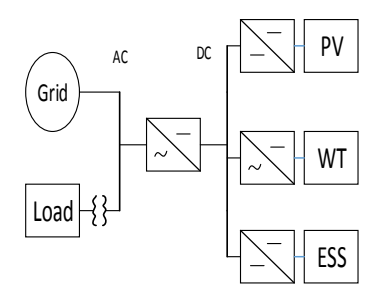

(a) DG side ESS

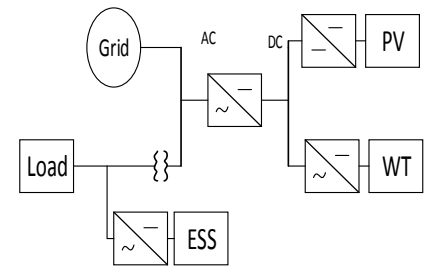

(b) Load side ESS
FIGURE I. MICROGRID WITH ESS INSTALLATION

\section{HESS APPLICATION}

To use HESS, the active topology used in this paper is shown in Fig. 2. The active topology is the most performance for HESS topology with the high cost of the converter [8]. However, this work is neglected. The BESS and SC are connected to the isolated bidirectional converter. This work used the ramp rate limitation to limit the power changed on the BESS as given in Eq. 1. If the energy storage required exceeds the ramp rate value, the power energy exchanges on BESS is limited and given in Eq. 2.

$$
\begin{gathered}
R a m P_{-} \text {Rate }=R R=\frac{\left[P_{E S S}(t)-P_{E S S}(t-1)\right]}{\Delta t} \\
P_{B E S S}(t)=R R \times \Delta t+P_{E S S}(t-1)
\end{gathered}
$$

where $P_{E S S}(t)$ and $P_{E S S}(t-1)$ are the current and previous signal of energy storages required respectively, $\Delta t$ is the total time changed.

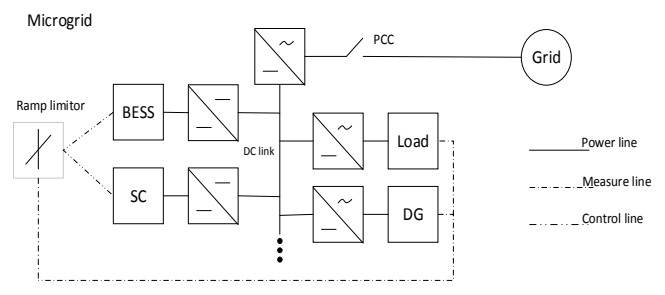

FIGURE II. SCHEMATIC DIAGRAM OF THE HESS

\section{SimUlATION AND RESUltS}

To evaluates the HESS application, the power mismatch $\left(P_{m}\right)$ of power generation from all DG and load demand in 1 hour of a microgrid is shown in Fig. 3. $P_{E S S}$ is the power required to charge/discharge of the ESS from the mismatch power; the positive or negative value is the power that wants to charge or discharge. The $P_{k}$ is the power exchanges between main grid and microgrid. This value intends to keep at a constant value for reducing the impact to the main grid, due to the fluctuation of power from a microgrid which leads the main grid to instability or failure. The power exchanged on the BESS and SC that satisfy the power energy storage required ( $P_{E S S}$ ) is shown in Fig. 4. Current transferred to each device is shown in Fig. 5. The SC can operate quickly with a rapid change of current for charging/discharging. For the BESS, the power exchanged gradually charge or discharge that serve to smooth current on BESS; it brings the safe operation of the BESS.

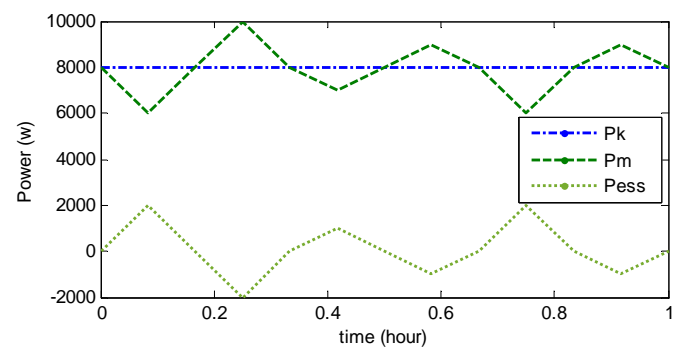

FIGURE III. POWER MISMATCH OF THE MICROGRID IN 1 HOUR

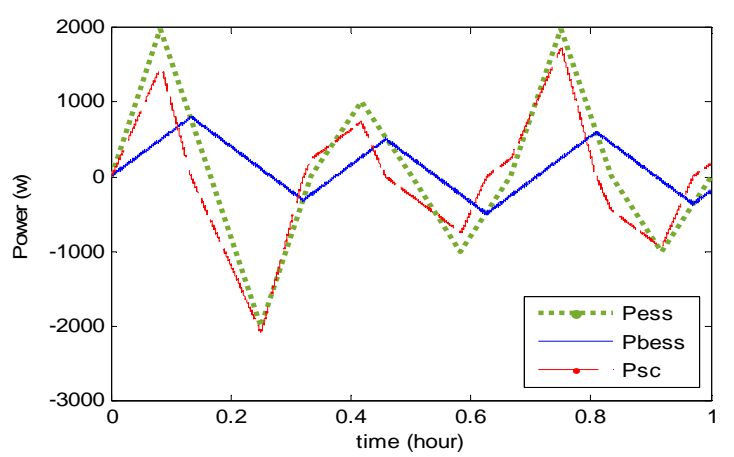

FIGURE IV. POWER OF BESS AND SC IN 1 HOUR 


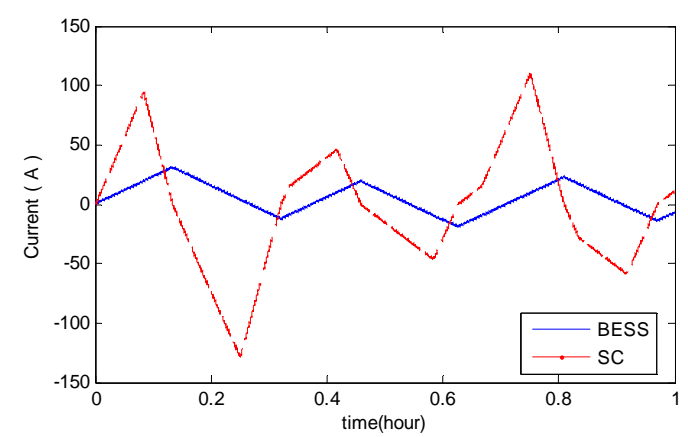

FIGURE V. CURRENT OF BESS AND SC IN 1 HOUR

\section{CONCLUSION}

The use of HESS to accommodate the fluctuation of power mismatch between load demand and power generation from DG was studied in this paper. Concerning the BESS and SC characteristics, the fast response to the rapid change or high rate current of charge/discharge in short time of SC was applied in a microgrid. Also, the BESS operates with high energy density property was used to support a microgrid for long time operation. The results showed that the smooth current on the BESS allowed the BESS work in an excellent condition. This method can extend the lifespan of BESS. From the mentioned above, this is the motivates to use the HESS that combines the advantages of each energy storage technology. However, the HESS needs the adept power electronic and control strategy to bring the most efficient operation.

\section{ACKNOWLEDGEMENT}

This work was supported by the Suranaree University of Technology.

\section{REFERENCES}

[1] K.K. Mehmood, S.U. Khan, S.J. Lee, Z.M. Haider, M.K. Rafique, C.H. Kim, Optimal sizing and allocation of battery energy storage systems with wind and solar power DGs in a distribution network for voltage regulation considering the lifespan of batteries, IET Renewable Power Generation. Vol. 11 (2017), pp. 1305-1315.

[2] D. Ansean, M. Dubarry, A. Devie, M. Gonzalez, Fast charging technique for high power LiFePO4 batteries: A mechanistic analysis of aging, Journal of Power Sources. Vol. 321 (2016), pp. 201-209.

[3] T.M. Bandhauer, S. Garimella, T.F. Fuller, A Critical Review of Thermal Issues in Lithium-Ion Batteries, Journal of The Electrochemical Society. Vol. 158 (2011).

[4] D.W. Gao, Energy storage for sustainable microgrid, 2015.

[5] M. Farhadi, M. Osama, Energy storage systems for high power applications. IEEE Industry Applications Society Annual Meeting, (2015).

[6] Y. Kim, V. Raghunathan, A. Raghunathan, Design and management of hybrid electrical energy storage systems for regulation services, International Green Computing Conference. (2014).

[7] X. Wang, M. Yue, E. Muljadi, W. Gao, Probabilistic Approach for Power Capacity Specification of Wind Energy Storage Systems, IEEE Transactions on Industry Applications, vol. 50 (2014), pp.1215-1224.

[8] W. Jing, C.H. Lai, S.H.W. Wong, M.L.D. Wong, Battery-Supercapacitor hybrid energy storage system in standalone DC microgrids: a review." IET Renewable Power Generation, vol. 11, no. 4, 2017, pp. 461-469. 